\title{
An approach to automation of a rational choice of adaptive agricultural technologies
}

\author{
Andrey Gostev ${ }^{1, *}$, Alexey Pykhtin ${ }^{2}$, and Sergey Tarasov ${ }^{1}$ \\ ${ }^{1}$ Kursk Federal Agricultural Research Center, ARRIAFSEC, 305021 Kursk, Russia \\ ${ }^{2}$ Southwest State University, Department of IT and new entrants, 305040 Kursk, Russia
}

\begin{abstract}
The research was conducted at the premises of the agricultural systems laboratory on the basis of research findings and analysis and generalization of modern scientific literature on a rational choice of adaptive technologies for cultivation of 10 crops (wheat, barley, rye, peas, millet, etc.) for different conditions in Russia. The most effective conditions for technologies application facilitating the efficient use of available resources were determined. Criteria, standards and requirements for the efficiency of the most important technological techniques of modern agricultural technologies were posed, as well as approaches to automation and an algorithm for their rational choice. The scheme and structure of the database of the agricultural producer support system for a rational choice of highly profitable adaptive technologies for leading grain crops cultivation were developed. The structure of the database of the decision support system is represented in three units: initial information, regulatory and reference information and calculation algorithms. The implementation of the developments into the production process opens up opportunities for the most efficient use of the existing soil and climate potential of the territories and material and technical resources in order to ensure highly profitable sustainable crops yields.
\end{abstract}

\section{Introduction}

The specificity of the adaptive landscape specific agriculture is the multivariance of agricultural technologies due to the diversity of cultivated crops and variability of soil and climate conditions in Russia [1]. Nowadays, a significant number of research findings has been accumulated, and their analysis enables a reasonable approach to the process of adaptation of agricultural technologies to different regions of the Russian Federation [2-4]. Domestic agricultural producers should use this information more actively to improve production efficiency, and scientists should proactively develop and distribute modern information technology products in the form of expert decisiontaking support systems on the most important agrotechnological issues to impart new knowledge and improve existing approaches to the design of science based agricultural technologies [5].

The purpose of our research is to develop modern approaches to automation and to create an algorithm for a rational choice of adaptive technologies for grain crop cultivation based on experimental data generalization, analysis and systematization considering the conditions of the European part of the Russian Federation. The research involves the development of the database structure of an agricultural support system facilitating a rational choice of highly profitable adaptive technologies of grain crops cultivation.

\section{Materials and methods}

Software development for a rational choice of an adaptive technology for cultivation of agricultural crops (Figure 1) is the final stage of the process of optimization of zonal agricultural technologies. The optimization process was implemented through the acquisition, analysis and synthesis of new knowledge about the regularities of yield formation and quality of products depending on the soil-climatic and material conditions in the framework of the general concept of resource conservation in agricultural production.

The study used a systemic approach, logical and mathematical analysis of the accumulated material, expert assessment methods, the theory of database management systems, the methodology of information systems design.

The subject of the research is adaptive agricultural technologies for grain crops cultivation. Based on the results of the All-Russian Agricultural Census conducted in 2016 [6], the largest acreage in the country is occupied with the following crops: wheat (27.8 million hectares), barley ( 8.4 million hectares), oats (3.0 million hectares), grain maize (2.9 million hectares), rye (1.3 million hectares), buckwheat (1.2 million hectares), peas (1.1 million hectares), millet (0.4 million hectares). Therefore, these crops were taken as a basis for the accomplishment of the purpose in hand.

* Corresponding author: aipykhtin@ @wsu.ru 


\begin{tabular}{|l|}
\hline $\begin{array}{c}\text { Acquisition of data of long-continued and short-term } \\
\text { field experiments on development and optimization of } \\
\text { technologies or certain techniques of crops cultivation }\end{array}$ \\
\hline $\begin{array}{c}\text { Analysis and generalization of the obtained data } \\
\text { and technical conditions, determining the most feasible } \\
\text { implementation of agrotechniques in a certain region of } \\
\text { the country }\end{array}$ \\
\hline $\begin{array}{c}\text { Development of reference database for the } \\
\text { implementation of adaptive crops cultivation } \\
\text { technologies }\end{array}$ \\
Development of a mathematical model and an algorithm \\
for selection of a crop cultivation technology taking into \\
account determinant factors and conditions \\
\hline Development of software enabling a science-based \\
decision-making on a rational choice of an adaptive crop \\
cultivation technology taking into account specificity of \\
the agricultural landscape and farming establishment
\end{tabular}

Fig. 1. Scheme of the development of a support system for agricultural producers for a rational choice of highly profitable adaptive technologies of cultivation of crops for different conditions of the Russian Federation.

The methodology for the rational choice of adaptive agricultural technologies includes consistent overcoming of the factors restricting crop yields and quality indicators of products while meeting the principles of resource conservation and environmental friendliness of technologies.

By "adaptive agrotechnology" we mean a complex of efficient agrotechnical methods for crops cultivation aimed at preserving or improving soil fertility and obtaining a high level of quality and biological safety of products with optimal labor costs and funds, taking into account the soil and climate, landscape and materialtechnical conditions prevailing in a particular territory.

The need for an adaptive approach to the process of selection of agricultural technologies is conditioned by several reasons:

- diversity of soil and climate conditions in the regions of the Russian Federation;

- differences in the level of provision of agricultural producers with material resources;

- development of new and improvement of the existing principles of formation of the structure of the cropping pattern and crop rotation under modern market economy conditions;

- development of agricultural machines and tools of a new generation that can take into account the terrain features and the state of crops, and contribute to labour productivity increase;

- appearance of new varieties and hybrids of crops, types of fertilizers and chemical crop protection products, approaches to their application, new ideas about the placement of micro and macronutrient elements in the soil layers, their migration, etc.

The algorithm for the choice of adaptive agricultural technologies is based on the consistent overcoming of the factors restricting the formation of the most profitable high-quality crop yield while meeting the principles of resource conservation. These factors include a natural and climatic zone, soil type, humus content, the degree of intensity of erosion processes, acidity, crop rotation, fertilizer and tillage systems, weed infestation, etc.

Moreover, the number of such factors may increase depending on the typicality of conditions and biological requirements of cultivated crops. So, for the most accurate algorithm for selecting adaptive agricultural technologies it is necessary to form a proper database including reference data facilitating efficient selection of highly profitable adaptive agrotechnologies based on the step-wise selection of agronomic practices taking into account the following approaches:

- optimization of the maximum possible number of technological techniques for different groups of crops with the scientific justification of each technique feasibility;

- definition of output parameters of technology (the predictable level of productivity, cost of production, energy intensity) on the basis of their simplified calculation;

- the use of a simplified modular database structure of the decision-taking support system for the rational choice of highly profitable adaptive crops cultivation technologies, which makes it possible to avoid listing the huge number of options of used machines, pesticides and fertilizers.

\section{Results and discussion}

Based on the analysis of the accumulated experimental material of long-term field experiments of the Kursk Federal Agricultural Research Center and generalization of the data of other research institutions of various regions of the European part of the Russian Federation and practical results of many agricultural enterprises, the most effective conditions for the rational choice of adaptive grain crop cultivation technologies, contributing to conservation of available resources of agricultural producers were first revealed. They were used to develop approaches to automation of a rational choice of adaptive agricultural technologies. Within the scope of these approaches, the structure of the database and then the algorithm of the support system for agricultural producers on a rational choice of highly profitable adaptive grain crops cultivation technologies were proposed.

The structure of the reference database of the support system for agricultural producers on the rational choice of highly profitable adaptive crops cultivation technologies is represented in three units: initial information, regulatory and reference information and calculation algorithms (Figure 2). 


\begin{tabular}{|c|}
\hline SOURCE DATA BLOCK \\
\hline Agroclimatic indicators: \\
\hline $\begin{array}{l}\text { - amount of annual rainfalls (mm per year); } \\
\text { - sum of temperatures (above } 10^{\circ} \mathrm{C} \text { ) }\end{array}$ \\
\hline $\begin{array}{c}\begin{array}{c}\text { Characteristics of the working } \\
\text { (elementary) sector: }\end{array} \\
\end{array}$ \\
\hline $\begin{array}{l}\text { Address: farm name, brigade or branch number, field } \\
\text { number, coordinate reference }\end{array}$ \\
\hline $\begin{array}{l}\text { Landscape: natural and climatic zone, slope exposure, } \\
\text { slope incline, intensity of erosion processes }\end{array}$ \\
\hline Soil: soil type and subtype, humus content, soil acidity \\
\hline $\begin{array}{l}\text { Agrotechnical information: a variety or hybrid of the } \\
\text { cultivated crop and the crop preceding it in rotation (the } \\
\text { precursor), the fertilizer doses used and the method of } \\
\text { basic tillage for the predecessor, the planned yield, } \\
\text { content of impurities, the timing of the planned crop }\end{array}$ \\
\hline rל \\
\hline $\begin{array}{c}\text { DATA BLOCK OF CALCULATION } \\
\text { ALGORITHMS } \\
\end{array}$ \\
\hline $\begin{array}{l}\text { - selection of adaptive technology of cultivation of the } \\
\text { chosen culture; } \\
\text { - approximate calculation of the economic efficiency of } \\
\text { technology; } \\
\text { - approximate calculation of the energy efficiency of the } \\
\text { technology }\end{array}$ \\
\hline THE REGULATORY INFORMATION BLOCK \\
\hline $\begin{array}{l}\text { - labor costs (manhour); } \\
\text { - costs of fuel (kg); } \\
\text { - need for fertilizers; } \\
\text { - productivity when performing agrotechnical practice } \\
\text { (ha per hour or t per hour); } \\
\text { - need for electricity (kw per hour). }\end{array}$ \\
\hline
\end{tabular}

Fig. 2. The structure of the reference database of the support system for agricultural producers on a rational choice of highly profitable adaptive technologies of grain crops cultivation.

Due to the fact that the scope of decision support system application is the European part of the Russian Federation, the analysis and synthesis of data of longterm and short-term field experiments on the development and optimization of technologies or individual techniques of crops cultivation should be performed for 8 regions: North, North-West, Central, Volga-Vyatka, Central Black Soil, North Caucasus, Middle Volga and Lower Volga regions. Naturally, each of them is characterized by a significant variety of soil and climate and landscape conditions, which should also be taken into account when forming a unit of initial information.

The Unit of regulatory and reference information includes six main criteria determining the efficiency and resource-saving orientation of agricultural technologies: the cost of labour (manhour), costs of fuel and lubricants $(\mathrm{kg})$, requirements for fertilizer ( $\mathrm{kg} /$ application rate) and pesticides (l or $\mathrm{kg}$ ), machine productivity (ha/h or $\mathrm{t} / \mathrm{h}$ ) and power demand $(\mathrm{kW} / \mathrm{h})$. Filling in the Unit of reference information and determining the values of the criteria, it is advisable to use regional registers of crops cultivation technologies (for example, Register of grain crop production technologies in the Central region of the Non-black soil area [3] or Register of technologies of production of grains, legumes, cereals and oil crops in the Volgograd region (system of technologies) [5])

The Unit of calculation algorithms includes three algorithms: a rational choice of adaptive technology of crops cultivation (for the selected conditions), assumptions of economic and energy efficiency of agricultural technologies.

Algorithms for calculating economic and energy efficiency of agricultural technologies involve automated forms of calculation of agricultural technologies efficiency based on common techniques [8-10].

For the first time the algorithm of a rational choice of the optimal adaptive technology of crops cultivation (Figure 3) was developed. It includes the following steps:

- a set of crops $C=\left(c_{j}\right), \quad j=\overline{1, N_{1}}$, a set of agrotechnologies $A=\left(a_{k}\right), k=\overline{1, N_{2}}$, a set of parameters $P=\left(p_{i}\right), i=\overline{1, N_{3}}$;
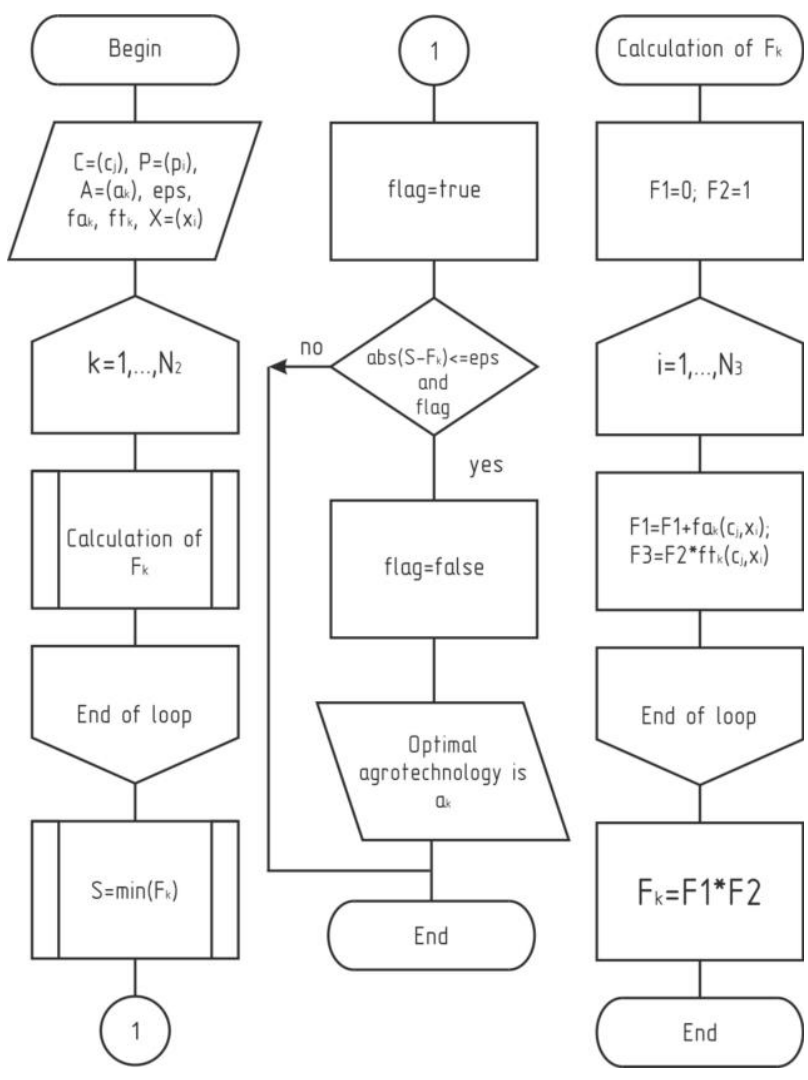

Fig. 3. Block diagram for the selection of the optimal agrotechnology.

- before the system starts work, functions (as a rule in a tabular form) of matching agrotechnologies to each parameter for different crops are defined and added to the database $f a_{k}\left(c_{j}, x_{i}\right)$. If the parameter is not used for the assessment of a certain crop agrotechnology, 
then $\forall k\left(f a_{k}\left(c_{j}, x_{i}\right)=0\right)$. Binary functions $f t_{k}\left(c_{j}, x_{i}\right)$ are also defined; their value equals to 1 , if parameter $p_{i}$ for agrotechnology $c_{j}$ can take value $x_{i}$. Otherwise $f t_{k}\left(c_{j}, x_{i}\right)=0$. These functions help to exclude agrotechnologies incompatible with important parameters (e.g. availability of the required amount of farm machinery, human resources, etc.);

- a user chooses analysed crop $c_{j}$ and inputs values of parameters

$$
\vec{x}=\left(x_{1}, x_{2}, \ldots, x_{i}, \ldots, x_{N_{3}}\right)
$$

- for each agrotechnology value

$$
F_{k}\left(c_{j}, \vec{x}\right)=\left(\sum_{i} f a_{k}\left(c_{j}, x_{i}\right)\right) \cdot\left(\prod_{i} f t_{k}\left(c_{j}, x_{i}\right)\right)
$$

is calculated; the maximum value

$$
S=\max _{k}\left\{F_{k}\left(c_{j}, \overrightarrow{\mathrm{x}}\right)\right\}
$$

is found;

- if $S$ value matches some agrotechnologies to a precision $\varepsilon$, defined by the system administrator, i.e.

$$
\left|S-F_{k}\left(c_{j}, \overrightarrow{\mathrm{x}}\right)\right| \leq \varepsilon
$$

for two and more values $k$, then the agrotechnology with the lowest cost is selected.

The algorithm has been tested on the Register of technologies for grain crops cultivation [7] by means of comparison of the decisions offered by the program and the opinion of four scientists-experts of the Kursk Federal Agricultural Research Center on the same initial data. Combinations of initial data were divided into "obvious", those for which the decision of all the experts coincided, "non-obvious" for which the choice of the optimal agricultural technology differed, and "acceptable" which were identified by the experts as acceptable agricultural technologies.

The results of the algorithm testing showed that in 95 $\%$ of the cases the program found solutions that agreed with the opinion of the experts for "obvious" options, in $100 \%$ of the cases the program recommendations did not find unacceptable solutions, in $90 \%$ of the cases for "non-obvious" variants, the program found solutions that experts assessed as acceptable.

Let us consider an example of food buckwheat. It is a forecrop "row crop" with the planned yield level of 16 t/ha. It tolerates the average level of effective soil fertility, is characterized with strong weed infestation of the field and requires application of plowing.

It has average lodging and fall resistance of the variety, requires provision of 5.5 manhour of direct labour per 1 ha of crops. Its material requirements include N30P30K30 kg a.r. of mineral fertilizers, $50 \mathrm{~kg}$ of fuel and lubricants, $0.5 \mathrm{~kg}$ of herbicides, $0.1 \mathrm{~kg}$ of fungicides, the 2 tractors per 100 hectares of crops, 1.5 ploughs, 0.5 cultivators, 0,8 windrowers and harvesters).

The algorithm recommends to use a basic-type technology due to the limited material resources, despite the possibility to use an intensive technology relevant to natural resources. This solution is optimal from the experts' point of view.

\section{Conclusion}

As the result of the research, the structure of database "A support system for agricultural producers for a rational choice of highly profitable adaptive grain crop cultivation technologies" was designed and developed. Its deployment in production will contribute to the generation, optimization and implementation of the existing agrotechnological solutions considering the variability of soil and climate and landscape conditions of agrarian areas, as well as producers' material and technical support.

Modern approaches to automation and an algorithm for a rational choice of adaptive technologies of cultivation of leading grain crops facilitating an objectoriented choice of the most expedient agrotechnologies, optimization of standards of mineral fertilizers and pesticides application rates, requirements for fuel and lubricants, which make it possible to reduce some negative impact on agroecosystems and environment and to increase profitability of production, are proposed.

\section{Acknowledgments}

The research was carried out within the framework of the Grant of the President of the Russian Federation for the state support of young Russian scientists - candidates of sciences No. MK-1064.2018.11.

\section{References}

1. I.I. Gureev, Bull. of Kursk State Agricultiral Academy, 2, 75 (2013)

2. S.Y. Plyansky, A.M. Pestryakov, E.V. Gureeva, Register of resource and energy efficient crop production technologies for Ryazan region (system of technologies) (SRI Ryazan Agricultural Research Institute, Ryazan, 2007)

3. Y.P. Lobachevsky, N.V. Voitovich, V.G. Egorov, Register of grain crop production technologies in Central region of Non-black soil area of RF (SRI Agricultural Research Institute of Central region of Non-black soil region, Moscow, 2003)

4. G.N. Cherkasov, I.G. Pykhtin, A.V. Gostev, L.B. Nitchenko, Achievements of science and technology of AIC, 12, 3 (2014)

5. A.S. Ovchinnikov, Register of production technologies for grain crops, grain legume, cereal and oil crops in Volgograd region (system of technologies) (Volgograd Agrarian University, Volgograd, 2014)

6. All-Russia Agricultural Census 2016. Preliminary conclusion: Bulletin of Statistics (Information and Publishing Centre "Statistics of Russia", Moscow, 2016)

7. I.G. Pykhtin, A.V. Gostev, A.I. Pykhtin, J. of Eng. and Applied Sciences, 20, 5338 (2017)

8. Methodology for economic assessment of technologies and machines in agriculture (All 
Russian Research Institute of Agriculture Economy, Moscow, 2018)

9. A.P. Barnes, I. Soto, V. Eory, Land use policy, 80, 163 (2019)
10. Methodology for energy analysis of technological processes in agriculture (VIM, Moscow, 2018) 